\title{
Lições que Podem ser Aprendidas da Rejeição de um Artigo
}

Lessons that can be Learned from the Rejection of an Article

Neste editorial eu gostaria de compartilhar com a comunidade um aprendizado: lições aprendidas do que um periódico científico pode proporcionar aos colegas pesquisadores ao optar por não publicar o manuscrito submetido. Em algum momento, a rejeição de trabalhos acontece com todos nós, e pode ser uma experiência de aprendizado e desenvolvimento (Sullivan, 2015).

Um dos aspectos mais frequentemente considerados na caracterização de distinção de um periódico científico é a sua taxa típica de aceitação, ou de rejeição, de submissões (McGrail, Rickard, \& Jones, 2006). Tendo em vista a relevância desse parâmetro para autores, editores e leitores, pesquisadores nas últimas décadas têm dedicado atenção a investigar variações de taxa de rejeição conforme a área de conhecimento, e evidentemente de um periódico para outro (Hargens, 1988).

Algumas revistas consideram todos os manuscritos recebidos como base para calcular essa taxa. Outras revistas permitem que o editor escolha quais artigos serão enviados aos revisores, e calcule a taxa de aceitação com base nos manuscritos que são revisados pelos pares, que evidentemente é menor que o total de manuscritos recebidos.

\footnotetext{
' Fundação Getulio Vargas, Escola de Administração de Empresas de São Paulo, São Paulo, SP, Brasil.

${ }^{2}$ Editor-chefe da RAC - Revista de Administração Contemporânea.
}

Além disso, alguns editores não mantêm registros precisos sobre esses dados e fornecem apenas uma estimativa aproximada. A esse respeito, os resultados encontrados por Hargens (1988), apontam ainda que a variação da quantidade de submissões não afeta a ocorrência de submissões, refutando o argumento de que a limitação de espaço para publicação explica a variação na taxa de rejeição.

Com frequência, indivíduos estão interessados em saber a taxa segundo a qual periódicos costumam aceitar submissões para publicação na oportunidade de escolha de um periódico para tal. A American Psychological Association (Summary Report of Journal Operations, 2018), por exemplo, costuma manter atualizados anualmente números acerca da taxa de rejeição em periódicos no campo de conhecimento de seu interesse. Essa entidade científica reporta percentual típico de $70 \%$ de rejeição entre as quase 12.000 submissões recebidas em 2017. Contudo, a identificação de taxas de aceitação praticada por periódicos, ou em disciplinas específicas, pode ser difícil.

Como citar: Mendes-da-Silva, W. (2020). Lessons that can be learned from the rejection of an article. Revista de Administração Contemporânea, 24(4), 369-375. https://doi.org/10.1590/1982-7849rac2020200069 
Apresentam-se como necessárias informações para atividades relacionadas à promoção e contratação de profissionais de pesquisa, dos quais se espera desempenho em termos de publicação (McGrail et al., 2006). Portanto, a decisão acerca de onde submeter trabalhos de pesquisa é algo relevante para profissionais de pesquisa (Heintzelman \& Nocetti, 2009). Com frequência assume-se que revistas com taxas mais baixas de aceitação de artigos são consideradas mais prestigiadas, ou até mesmo mais meritórias.

Todos nós recebemos cartas de rejeição de artigos submetidos, às vezes mais que desejaríamos receber. De fato, é desanimador quando um manuscrito, fruto de árduo trabalho de pesquisa, é rejeitado por um periódico científico. Os indivíduos pesquisadores trabalham muito para realizar pesquisas. Eles frequentemente apresentam seu trabalho em conferências, e/ou submetem artigo de pesquisa para publicação. Quando suas apresentações são aplaudidas pelo público, pesquisadores sentem-se incentivados a publicar seus artigos. No entanto, seus trabalhos, por diferentes motivos, podem acabar não sendo priorizados pelos editores e revisores quando a pesquisa é submetida a uma revista (Khadilkar, 2018).

\section{RAZÕES PARA A REJEIÇÃO DO MANUSCRITO PARA PUBLICAÇÃO}

Existem razões diversas pelas quais um trabalho pode ter sido rejeitado para publicação (Besancenot, Huynh, \& Vranceanu, 2011). A maioria dos editores de periódicos costuma detalhar os motivos da decisão ao final do processo de avaliação, preservando a transparência do processo editorial (Mendes-Da-Silva, 2018a). Em geral, os artigos atribuídos a desk reject (rejeitados antes da revisão externa, pelos pares) recebem essa comunicação devido a quatro motivos principais: a) ter problemas significativos relativos a linguagem ou estrutura; b) não estar em conformidade suficiente com as orientações para autores; c) não ser um tópico abordado pela revista; ou d) não explicitar de maneira convincente as suas contribuições para o campo de conhecimento.

Em princípio, autores podem pensar que os dois primeiros motivos seriam insuficientes para rejeitar um manuscrito. Porém, há que se realçar que o editor pode estar (e deve estar) trabalhando com vários artigos novos ao mesmo tempo. É de responsabilidade do autor assegurar que seu documento esteja escrito e estruturado corretamente, em observância às diretrizes da revista. A RAC tem relaxado uma série de requisitos julgados demasiadamente específicos na oportunidade da submissão, à guisa de tornar a vida dos autores menos entediante. A RAC tem se concentrado em aspectos básicos, mas igualmente importantes, na fase preliminar do processo editorial.
Mas, em caso de aceite, o escritório editorial não abre mão dos requisitos inicialmente relaxados.

Um aspecto adicional a respeito da taxa de rejeição é: o número de pessoas atuantes na pesquisa em determinado campo de conhecimento pode ser diminuto, dado o nível típico de especialização. Isto pode influenciar a taxa de aceitação, portanto. Desse modo, acaso eventualmente apenas algumas pessoas possam escrever trabalhos em uma determinada área, pode haver tendência pelo aumento da taxa de aceitação da revista naquele nicho.

Por outro lado, acaso o trabalho seja rejeitado após a revisão pelos pares externos (que frequentemente passam a ser conhecidos na ocasião da publicação do artigo, no caso na RAC), é provável que tenha sido notado um ou mais problemas acerca o conteúdo do artigo. A comunicação da decisão de rejeição deve especificar os motivos apontados pelos revisores, muito embora o editor não necessariamente esteja obrigado a seguir as sugestões e recomendações dos revisores, seja para aceitar ou rejeitar o artigo.

Você deve esperar ver comentários detalhados dos revisores, juntamente com um comentário do editor (se isso não acontecer imediatamente, você tem toda a justificativa de pedir - educadamente uma explicação do periódico). Independentemente do momento - e do(s) motivo(s) - para dizer "não, obrigado". No entanto, existem algumas estratégias que você pode adotar para buscar alternativas para publicar seu trabalho. Adiante segue uma lista não exaustiva de motivos para rejeição de um trabalho submetido, seja já no desk review, ou na fase de julgamento pelos pares, i.e. double blind peer review.

\section{Motivos principais para rejeição já na desk review:}

- O artigo e o assunto podem estar fora do escopo, e não serem considerados adequados para a revista, e os leitores.

- A contribuição para a literatura não está devidamente argumentada, o Estado-da-Arte não se encontra suficientemente estabelecido, ou a hipótese central apresenta-se fraca.

- Os autores não discutem os cuidados tomados acerca da validade dos resultados de sua pesquisa (incluindo-se estudos que utilizam abordagem qualitativa).

- O método apresenta-se limitado em demasiado, a amostra apresenta-se pequena sem a devida justificativa para tal, a análise estatística ou econométrica mostra-se inadequada.

- Mesmo sendo necessária, a permissão de um comitê de ética não está declarada na submissão.

- A literatura documenta haver pesquisas semelhantes já publicadas.

- Plágio suspeito ou confirmado. 
A redação do trabalho não está compatível com um trabalho científico, e/ou não é caracterizada por nível adequado de fluidez.

\section{Motivos principais para rejeição após double blind peer review:}

- Os objetivos perseguidos pelos autores não levam a perguntas de pesquisa contributivas para a literatura, e o background apresentado não se apresenta com clareza de pensamento suficiente.

- Os dados estão incompletos/insuficientes, e a seção de metodologia apresenta deficiências irreparáveis.

- As instruções aos autores não foram seguidas atentamente.

- As figuras são de baixa resolução, e as tabelas são muito complicadas e não são compreensíveis.

- Discussão e conclusões não respondem aos objetivos da pesquisa.

- Existe incompatibilidade entre as declarações feitas em diferentes seções do paper.

- Os editores/revisores do manuscrito sentem que os autores não trabalharam o suficiente na apresentação/discussão/análise dos dados. Os autores têm a total responsabilidade de revisar, quantas vezes forem necessárias, para obter uma apresentação profissional e impecável do manuscrito.

- Existe falta geral de elementos-chave que caracterizam uma boa pesquisa, como: hipóteses fortes, metodologia impecável, resultados bem apresentados, e discussão aprofundada com recomendações e conclusões relevantes e contributivas para o campo de conhecimento.

- Linguagem ruim e muitos erros ortográficos e gramaticais criam uma má impressão nos revisores.

Em síntese, os motivos mais comuns de decisões editoriais que recomendam devolver o manuscrito aos seus autores são essencialmente: metodologia pobre e/ou não haver informações novas. De um modo geral, um conteúdo científico pobre induz a rejeição de uma submissão.

\section{O QUE PODEMOS FAZER APÓS RECEBER UMA COMUNICAÇÃO DE REJEIÇÃO?}

É evidente que não se espera uma reação positiva de um indivíduo pesquisador que acaba de ter um trabalho rejeitado. Ao mesmo tempo, sabemos que o caminho para a publicação não é algo tipicamente fácil. Todo indivíduo autor terá que lidar com a possível situação de rejeição de trabalhos submetidos ao longo de sua carreira, a menos que decida não submeter suas pesquisas para publicação. Mas, existe a opção de tentar transformar a situação em algo que permita obter um espaço para publicação de seu paper. Assim, a pessoa que trabalha em pesquisa pode ver o lado positivo de uma decisão editorial negativa, e aproveitar ao máximo a chance de obter sucesso na próxima vez que submeter seu trabalho (Heintzelman \& Nocetti, 2009).

Sullivan (2015) realça que, tanto autores em início de carreira, como também aqueles já estabelecidos, terão a experiência de ter papers rejeitados. Em resposta a uma comunicação de rejeição, não se deve reagir simplesmente excluindo a mensagem. Sobretudo, deve-se evitar a decisão de nunca mais escrever outro artigo. Sugerindo estratégias de comportamentos a evitar, seguem alternativas para encontrar um caminho para a sua pesquisa (Figura 1).

Em síntese, lide primeiro com o pior cenário: seu artigo simplesmente ser visto como não tendo qualidade suficiente para publicação. Essa notícia pode trazer algo contributivo, e isso pode ajudar você a perceber que existe algo a ser feito antes mesmo de começar a pensar para onde pode enviar seu paper (Heintzelman \& Nocetti, 2009). Portanto, tente não ignorar o feedback que você recebe de um periódico, mesmo que seja algo desagradável. Concentre-se no lado positivo: seu trabalho obteve o benefício de receber a opinião de colegas, que dedicaram atenção total ao trabalho que você submeteu. Assim, a melhor estratégia é sempre dispensar mais atenção ao que eles dizem, em lugar de sair correndo, e enviar exatamente o mesmo conteúdo para outro periódico.

Pode ser frustrante ter seu trabalho rejeitado com algo similar a ser considerado 'fora do escopo' da revista, mas tente novamente ver isso como um aprendizado. Nesse sentido, pode ser melhor que seja rejeitado logo no início, permitindo que você identifique um periódico mais adequado (por vezes, o editor pode se dar ao trabalho de sugerir um para você!), em vez de esperar várias semanas, ou meses, até receber a mesma notícia. Da mesma forma, ser recusado devido a erros de linguagem ou estruturais permite corrigir esses problemas antes de tentar novamente. Tente ver cada estágio (mesmo que pareça que você está regredindo, em lugar de avançar na busca de uma publicação) como uma oportunidade para (ainda mais) melhorar seu artigo.

Se você foi rejeitado após a revisão pelos pares, aproveite as informações do editor e dos revisores, e faça um esforço consciente para processar o feedback. Isso permitirá que você dê ao seu artigo a melhor chance de sucesso quando for enviar para outro lugar. 


\begin{tabular}{|c|c|}
\hline Estratégia & Atitude \\
\hline $\begin{array}{l}\text { Controle seus } \\
\text { impulsos }\end{array}$ & $\begin{array}{l}\text { Antes de tudo, controle seus sentimentos. A rejeição de manuscritos é especialmente mais difícil para autores } \\
\text { no início de suas carreiras. É melhor identificar suas emoções e empregar seus melhores mecanismos de } \\
\text { enfrentamento, pois cada pessoa acaba adotando sua própria estratégia para compensar notícias contrárias } \\
\text { às suas expectativas. Depois de retomar seu estado de espírito mais calmo, busque avaliar racionalmente } \\
\text { motivos pelos quais seu trabalho pode não ter sido aceito. Evite levar as coisas para a esfera pessoal. }\end{array}$ \\
\hline $\begin{array}{l}\text { Leia cuidadosamente } \\
\text { a comunicação } \\
\text { de rejeição, } \\
\text { especialmente os } \\
\text { pareces recebidos }\end{array}$ & $\begin{array}{l}\text { A comunicação da rejeição deve ser lida com o merecido cuidado, especialmente se acaso você teve a sorte } \\
\text { de receber um parecer mais elaborado, feito por um pesquisador que mantém a disciplina e os cuidados } \\
\text { necessários ao adequado julgamento de manuscritos submetidos (Mendes-Da-Silva, 2018b). Evite ler a } \\
\text { comunicação de rejeição indo direto à frase que não desejaria ler; explore o conteúdo do e-mail. É comum } \\
\text { recebermos, nas editorias, perguntas que já estão explicitamente respondidas na comunicação de rejeição } \\
\text { do manuscrito. Por vezes, artigos são rejeitados sem a revisão por pares externos. Nesse caso, editores } \\
\text { revisarão o artigo para determinar a relevância para o público da revista, nivelar com artigos recentemente } \\
\text { aceitos, e a qualidade geral dos trabalhos recentemente publicados. Os artigos que não passarem nesse } \\
\text { filtro inicial serão rejeitados sem revisão pelos pares. Algumas revistas não fornecem nenhuma informação } \\
\text { adicional. Mas, nas situações em que você receber explicações de motivos pelos quais a revista decidiu } \\
\text { daquela forma, revise cuidadosamente os comentários, eles certamente serão úteis para o progresso e o } \\
\text { desenvolvimento da sua pesquisa. }\end{array}$ \\
\hline $\begin{array}{l}\text { Siga as orientações } \\
\text { aos autores }\end{array}$ & $\begin{array}{l}\text { No processo de revisão de muitos periódicos, os artigos que não seguirem cuidadosamente as instruções } \\
\text { aos autores em termos de formato, contagem de palavras, quantidade de figuras e tabelas, assim como o } \\
\text { estilo de referência, serão rejeitados imediatamente. Apesar de sua complexidade, as instruções do autor } \\
\text { devem ser seguidas cuidadosamente; qualquer desvio deve ser tratado claramente na carta de apresentação } \\
\text { aos editores da revista. O envio de um artigo que não segue as instruções aos autores atrasa a revisão do seu } \\
\text { artigo. Portanto, seguir as instruções aos autores é o primeiro passo para ter um artigo aceito. }\end{array}$ \\
\hline $\begin{array}{l}\text { Alinhe o seu } \\
\text { manuscrito com o } \\
\text { escopo do periódico }\end{array}$ & $\begin{array}{l}\text { Um motivo comum para desk reject de artigos submetidos é uma incompatibilidade entre o artigo e o escopo } \\
\text { da revista, o qual está relacionado ao público-alvo da revista. Embora o título de uma revista forneça algumas } \\
\text { informações sobre seu escopo, mais informações serão encontradas em seu site. É altamente recomendável } \\
\text { revisar algumas edições da revista, examinando seu conteúdo e seu formato, antes de enviar seu artigo. }\end{array}$ \\
\hline $\begin{array}{l}\text { Busque mais dados } \\
\text { e/ou reorganize a } \\
\text { rotina de análise }\end{array}$ & $\begin{array}{l}\text { Trabalhos quantitativos que exploram uma nova intervenção educacional são frequentemente limitados } \\
\text { pelo pequeno "n" dos sujeitos em estudo. Muitas das populações que estudamos - instituições, empresas, } \\
\text { ou indivíduos - são limitadas naturalmente. No entanto, o tamanho da amostra pode ter sido muito pequeno } \\
\text { para encontrar uma associação (um erro do tipo II). Amostras pequenas também limitarão expressivamente } \\
\text { a validade dos resultados. No entanto, a coleta de dados sobre assuntos adicionais, por exemplo, repetindo } \\
\text { uma intervenção por vários anos, pode gerar resultados mais esclarecedores e credíveis. }\end{array}$ \\
\hline $\begin{array}{l}\text { Considere a } \\
\text { ressubmissão ao } \\
\text { mesmo periódico }\end{array}$ & $\begin{array}{l}\text { Se os problemas citados na comunicação de rejeição da submissão referirem-se a etapas ou resultados que } \\
\text { você executa, mas, por algum motivo, foram omitidos em seu trabalho, você poderá refazer a submissão } \\
\text { de seu manuscrito, incluindo os métodos, ou dados, incialmente ausentes. Mas é aconselhável verificar } \\
\text { primeiro com o escritório editorial do periódico. Antes de revisar seu artigo para ajustar a uma possível } \\
\text { categoria diferente, considere também outra revista, com um escopo ou público-alvo diferente. }\end{array}$ \\
\hline $\begin{array}{l}\text { Ajuste o paper para } \\
\text { submeter a um novo } \\
\text { periódico }\end{array}$ & $\begin{array}{l}\text { Não raramente, os mesmos revisores podem ser solicitados a ler seu artigo para a nova revista. Portanto, } \\
\text { é imperativo fazer todas as alterações apropriadas tomando por base o feedback já fornecido na revisão } \\
\text { inicial. Quando não viável conduzir alterações substanciais - como a coleta de novos dados - solicitada } \\
\text { pelos revisores iniciais, pode ser prudente incluir uma justificativa em sua carta de apresentação, ou em } \\
\text { um apêndice suplementar ao artigo da nova submissão. Se essas informações não forem fornecidas com } \\
\text { precisão, o documento será rejeitado. E, geralmente, os editores não assumem como incomodo receber um } \\
\text { manuscrito que foi revisado anteriormente. Isto porque o artigo geralmente está em melhor forma geral: } \\
\text { mais conciso e claro. Use todo o valioso feedback que você recebeu das primeiras críticas e direcione seu } \\
\text { trabalho para o periódico eventualmente mais alinhado. }\end{array}$ \\
\hline
\end{tabular}

Figura 1. Sugestões de estratégias para melhor aproveitamento do feedback no processo de avaliação de manuscritos submetidos.

Fonte: Adaptado de Sullivan, G. M. (2015). What to do when your paper is rejected. Journal of Graduate Medical Education, 7(1), 1-3. https://doi.org/10.4300/JGME-D-14-00686.1.

Com frequência, várias pessoas experientes no tópico doaram voluntariamente um tempo substancial para fornecer aconselhamento detalhado para aprimorar seu trabalho submetido. Tente usar essa valiosa informação para aprimorar seu artigo para submissão a outro periódico, bem como seu próximo, e possivelmente mais robusto, paper. Considere, também, voluntariar-se para revisar artigos em periódicos. Isto faz parte do exercício da cidadania no mundo da gestão de negócios, além de especialmente colaborar para melhorar suas próprias habilidades de pesquisador no seu respectivo campo de conhecimento.

No caso particular da RAC, destacamos que este periódico mantém práticas que o diferenciam de periódicos caracterizados como predatórios, ou de baixa qualidade em consequência de revisões sofríveis (Mendes-Da-Silva, 2018b; Van Noorden, 2020). Aproveito mais esta oportunidade para recorrer às reflexões de Engers e Gans (1998), e 
realçar o agradecimento desta editoria da RAC às pessoas que voluntariamente doam seu valioso tempo para emitir, de mente e coração abertos, pareceres detalhados para trabalhos submetidos pelos nossos pares.

\section{ARTIGOS PUBLICADOS NESTA EDIÇÃO}

A RAC continua empenhada no propósito de adotar políticas de ciência aberta (Mendes-Da-Silva, 2018a; 2019; 2020; Martins, 2020). Além do acesso aberto e irrestrito aos documentos publicados, a RAC vem publicando desde julho de 2018 artigos com dados abertos. E, desde o início de 2020, vem publicando o conjunto de revisores (mediante anuência desses), que atuam no processo via double blind peer review, na ocasião da publicação dos respectivos artigos publicados. Nesta edição, a RAC publica cinco artigos inéditos conforme adiante descritos.

O primeiro artigo, intitulado 'Antecedentes Psicossociais e Organizacionais do Compartilhamento de Conhecimento no Ambiente de Trabalho', de autoria de Valter Moreno, Flávia Cavazotte e Janicélio Pereira Dutra (Moreno, Cavazotte, \& Dutra, 2020), propõe e avalia um modelo sobre compartilhamento de conhecimento entre pares no ambiente de trabalho. Os autores testaram o modelo via equações estruturais, a partir de dados fornecidos por 131 funcionários atuantes no atendimento ao cliente de uma grande empresa brasileira de telecomunicações. O artigo possui dados abertos à comunidade.

O segundo artigo inédito (Lewin \& Campani, 2020) publicado nesta edição é de autoria de Marcelo Lewin e Carlos Heitor Campani, tem como título 'Gestão de Carteiras sob Múltiplos Regimes: Estratégias que Performam Acima do Mercado', e também possui dados abertos à comunidade. Esse trabalho avalia estratégias de investimento em portfólio, e compara suas performances com retornos apresentados por benchmarks. Para isto, os autores propõem estratégias com, e sem, vendas a descoberto sob quatro regimes econômicos latentes a partir dos retornos dos ativos: cash (CDI), renda fixa, ações domésticas, e ações internacionais em reais. Os autores defendem que são pioneiros ao identificar, pela primeira vez, quatro regimes econômicos no Brasil para otimização de carteiras. Os resultados indicam que a política de portfólio depende fortemente do estado corrente da economia, e ainda que as estratégias propostas superam o mercado.

O terceiro artigo inédito (Lima, Nassif, \& Garçon, 2020) tem como título 'O Poder do Capital Psicológico: A Força das Crenças no Comportamento
Empreendedor', e é de autoria de Luciano Gonçalves de Lima, Vânia Maria Jorge Nassif e Marcia Maria Garçon. O objetivo central declarado pelos autores é analisar o comportamento empreendedor a partir dos componentes do capital psicológico e da teoria social cognitiva. Para tanto, os autores empregam uma abordagem de pesquisa qualitativa, com entrevistas em profundidade, com duas dezenas de empreendedores. Os resultados sugerem que as ações desenvolvidas pelos entrevistados no decorrer da criação e desenvolvimento do negócio estão alinhadas às características empreendedoras conforme a literatura, independente de gênero, idade ou tempo de atuação. A conclusão principal é que as forças psicológicas atuam como elementos fundamentais para o sucesso do empreendedor.

'Principais Direcionadores de Compra de Carnes em Hipermercados', escrito por Lierk Kalyany Silva de Sousa, Vânia Ferreira Roque-Specht e Eduardo Monteiro de Castro Gomes, é o quarto artigo inédito (Sousa, Roque-Specht, \& Gomes, 2020) que publicamos nesta edição, e também possui dados abertos à comunidade. Os autores apontam como objetivo do trabalho: analisar os principais fatores associados ao consumo das carnes bovina, suína e de frango. Para isto, os autores utilizam dados coletados no Distrito Federal do Brasil, em três redes distintas de hipermercados. Realizou-se uma avaliação socioeconômica dos entrevistados, seguida da aplicação de um survey, por meio de sentenças afirmativas estruturadas, categorizadas em dimensões sociocultural, econômica, saúde/ alimento e ambiente. A conclusão dos autores é que o controle de qualidade de exposição das carnes nos supermercados, e a praticidade de encontrar o mesmo tipo de carne em vários locais são os principais influenciadores de tomada de decisão de compra.

Por fim, o quinto artigo inédito (Cruz, Falcão, Barbosa \& Paula, 2020) publicado neste quarto número da RAC em 2020, é intitulado 'Análise de Variáveis Prescritoras da Intenção Empreendedora de Imigrantes Brasileiros em Portugal', e possui como autores Eduardo Picanço Cruz, Roberto Pessoa de Queiroz Falcão, Yan Orge Fernandes Barbosa, e Fábio de Oliveira Paula. Este artigo possui dados com acesso aberto à comunidade, em linha com práticas de ciência aberta. Os autores argumentam que o estudo busca identificar variáveis prescritoras da intenção empreendedora de imigrantes brasileiros em Portugal. Os autores utilizam dados relativos a mais de 660 respondentes brasileiros habitantes de Portugal, e usam modelos logit.

Convidamos todos à leitura deste número. 


\section{REFERÊNCIAS}

Summary Report of Journal Operations, 2017 (2018). American Psychologist, 73(5), 683-684. http://dx.doi. org/10.1037/amp0000347

Besancenot, D., Huynh, K., \& Vranceanu, R. (2011). A matching model of the academic publication market. Journal of Institutional and Theoretical Economics, 167(4), 708725. http://dx.doi.org/10.1628/jite-2011-0010

Engers, M., \& Gans, J. (1998). Why referees are not paid (enough). The American Economic Review, 88(5), 13411349. Retrieved from www.jstor.org/stable/116875

Hargens, L. (1988). Scholarly consensus and journal rejection rates. American Sociological Review, 53(1), 139-151. http://dx.doi.org/10.2307/2095739

Heintzelman, M., \& Nocetti, D. (2009). Where should we submit our manuscript? An analysis of journal submission strategies. The B.E. Journal of Economic Analysis \& Policy, 9(1). http://dx.doi.org/10.2202/19351682.2340

Khadilkar, S. S. (2018). Rejection blues: Why do research papers get rejected?. Journal of Obstetrics and Gynecology of India, 68(4), 239-241. https://doi.org/10.1007/ s13224-018-1153-1

Lewin, M., \& Campani, C. H. (2020). Portfolio management under multiple regimes: Strategies that outperform the market. Revista de Administração Contemporânea, 24(4), 300-316. https://doi.org/10.1590/19827849rac2020190161

Lima, L. G. de, Nassif, V. M. J., \& Garçon, M. M. (2020). The power of psychological capital: The strength of beliefs in entrepreneurial behavior. Revista de Administração Contemporânea, 24(4), 317-334. https://doi. org/10.1590/1982-7849rac2020180226

Martins, H. C. (2020). The importance of open science in business research. Revista de Administração Contemporânea, 24(1). https://doi.org/10.1590/19827849rac2020190380

McGrail, M. R., Rickard, C. M., \& Jones, R. (2006). Publish or perish: A systematic review of interventions to increase academic publication rates. Higher Education Research and Development, 25(1), 19-35. https://doi. org/10.1080/07294360500453053

\section{Autores}

\section{Wesley Mendes-Da-Silva*}

Rua Itapeva, 474, $8^{\circ}$ andar, 01332-000, São Paulo, SP, Brasil.

E-mail: rac.wesley.mendes@gmail.com

๑ https://orcid.org/0000-0002-5500-4872

* Autor Correspondente

\section{Conflito de Interesses}

O autor informou que não há conflito de interesses.

\section{Direitos Autorais}

A RAC detém os direitos autorais deste conteúdo.
Mendes-Da-Silva, W. (2018a). The promotion of transparency and the impact of research on business. Revista de Administração Contemporânea, 22(4). https://doi. org/10.1590/1982-7849rac2018180210

Mendes-Da-Silva, W. (2018b). Reconhecimento da contribuição do avaliador anônimo. Revista de Administração Contemporânea, 22(5). https://doi.org/10.1590/19827849rac2018180281

Mendes-Da-Silva, W. (2019). Have we been transparent enough? Challenges in replicability and credibility in business research. Revista de Administração Contemporânea, 23(5). https://doi.org/10.1590/19827849rac2019190306

Mendes-Da-Silva, W. (2020). Meus dados, minha vida: Objetivos individuais e papel da comunidade de pesquisadores na área de negócios. Revista de Administração Contemporânea, 24(2), 197-200. https://doi. org/10.1590/1982-7849rac2020190403

Moreno, V., Cavazotte, F., \& Dutra, J. P. (2020). Psychosocial and organizational antecedents of knowledge sharing in the workplace. Revista de Administração Contemporânea, 24(4), 283-299. https://doi.org/10.1590/19827849rac2020190239

Cruz, E. P., Falcão, R. P. de Q., Barbosa, Y. O. F., \& Paula, F. de O. (2020). Analysis of prescribing variables of entrepreneurial intention of brazilian immigrants in Portugal. Revista de Administração Contemporânea, 24(4), 349-368. https://doi.org/10.1590/19827849rac2020190409

Sousa, L. K. S. de, Roque-Specht, V. F., \& Gomes, E. M. de C. (2020). Main hypermarket meat purchasing drivers. Revista de Administração Contemporânea, 24(4), 335-348. https://doi.org/10.1590/1982- 7849rac2020190097

Sullivan, G. M. (2015). What to do when your paper is rejected. Journal of Graduate Medical Education, 7(1), 1-3. https://doi.org/10.4300/JGME-D-14-00686.1

Van Noorden, R. (2020, March 11). Hundreds of scientists have peer-reviewed for predatory journals. Nature, News. https://doi.org/10.1038/d41586-020-00709-x

\section{Corpo Editorial Científico e Equipe Editorial para esta edição:}

\section{Conselho Editorial}

Anielson Barbosa da Silva (UFPB, João Pessoa, Brasil) Antonio Carlos Gastaud Maçada (UFRGS, Porto Alegre, Brasil) Ely Laureano Paiva (FGV, São Paulo, Brasil)

Fabio Vizeu Ferreira (UP, Curitiba, Brasil)

Maria José Tonelli (FGV, São Paulo, Brasil)

Rogério Hermida Quintella (NPGA/UFBA, Salvador, Brasil)

Valmir Emil Hoffmann (UnB, Brasília, Brasil)

Wesley Mendes-da-Silva (EAESP/FGV, São Paulo, Brasil) 
Editor-chefe

Wesley Mendes-da-Silva (EAESP/FGV, São Paulo, Brasil)

\section{Editores Associados}

André Luiz Maranhão de Souza-Leão (UFPE, Recife, Brasil)

Fabio Caldieraro (EAESP/FGV, São Paulo, Brasil)

Gilnei Luiz de Moura (UFSM, Santa Maria, Brasil)

Henrique Castro Martins (IAG PUC-Rio, Rio de Janeiro, Brasil)

Ismael Ali Ali (Kent State University, Ohio, EUA)

Marcus Cunha Junior (University of Georgia, EUA)

Paula Castro Pires de Souza Chiment (UFRJ/Coppead, Rio de Janeiro, Brasil)

Paulo César Matui (UniGranRio, Rio de Janeiro, Brasil)

Samy Dana (FGV/EAESP, São Paulo, Brasil)

\section{Corpo Editorial Científico}

Aureliano Angel Bressan (CEPEAD/UFMG, Belo Horizonte, Brasil)

Bryan Husted (York University, Canadá)

Carlos M. Rodriguez (Delaware State University, EUA)

Cristiana Cerqueira Leal (Universidade do Minho, Portugal)

Diógenes de Souza Bido (Mackenzie, São Paulo, Brasil)

Elin Merethe Oftedal (University of Tromsø, Noruega)

Emilio Jose Monteiro Arruda Filho (Unama, Belém, Brasil)

Fábio Frezatti (FEA/USP, São Paulo, Brasil)

Felipe Monteiro (Wharton/University of Pennsylvania, EUA)

Howard J. Rush (University of Brighton, Reino Unido)
James Robert Moon Junior (Georgia Institute of Technology, EUA)

John L. Campbell (University of Georgia, EUA)

José Antônio Puppim de Oliveira (United Nations University, Yokohama, Japão)

Julián Cárdenas (Freie Universität, Berlin, Alemanha)

Lucas Barros (EAESP/FGV, São Paulo, Brasil)

Luciano Rossoni (UniGranRio, Rio de Janeiro, Brasil)

M. Philippe Protin (Université Grenoble Alpes, França)

Paulo Estevão Cruvinel (Embrapa Instrumentação, São Carlos, Brasil)

Rodrigo Bandeira de Mello (Merrimack College, EUA)

Rodrigo Verdi (MIT Massachusetts Institute of Technology, Cambridge, EUA)

Valter Afonso Vieira, (UEM, Maringá, Brasil)

Wagner Kamakura (Jones Graduate School of Business, Rice University, Houston, EUA)

\section{Editoração}

Diagramação e Normas da APA: Kler Godoy (ANPAD, Maringá, Brasil)

Periodicidade: Bimestral.

Circulação: Acesso totalmente gratuito. 